\title{
An Empirical Analysis of Factors Affecting Obesity in the Alabama Black Belt and Surrounding Counties
}

\author{
Nii O. Tackie (Corresponding author) \\ Department of Agricultural and Environmental Sciences, Tuskegee University \\ 204 Morrison-Mayberry Hall, Tuskegee, AL 36088, USA \\ Tel: 1-334-727-8813 E-mail: ntackie@mytu.tuskegee.edu
}

Gwendolyn J. Johnson

Cooperative Extension Program, Tuskegee University

204 Morrison-Mayberry Hall, Tuskegee, AL 36088, USA

Tel: 1-205-372-2107 E-mail: gjjohnson@mytu.tuskegee.edu

Millicent P. Braxton

Cooperative Extension Program, Tuskegee University

204 Morrison-Mayberry Hall, Tuskegee, AL 36088, USA

Tel: 1-334-548-2325 E-mail:mbraxton@mytu.tuskegee.edu

\begin{abstract}
Benedicta Obeng
Cooperative Extension Program, Tuskegee University

204 Morrison-Mayberry Hall, Tuskegee, AL 36088, USA

Tel: 1-334-724-4440Ｅ-mail: bobeng6576@mytu.tuskegee.edu
\end{abstract}

Beatrice Sampson

Cooperative Extension Program, Tuskegee University

204 Morrison-Mayberry Hall, Tuskegee, AL 36088, USA

Tel: 1-334-724-4440_E-mail: bsampson0458@mytu.tuskegee.edu 
Received: November 13, 2014 Accepted: December 15, 2014 Published: December 16, 2014

doi:10.5296/jsss.v2i1.792ＵRL: http://dx.doi.org/10.5296/jsss.v2i1.6792

\begin{abstract}
Overweight and obesity have been major challenges over the last several decades. The study analyzed factors affecting obesity in the Alabama Black Belt and surrounding counties. Using a questionnaire, data were obtained from a convenience sample of 273 participants from several counties, and analyzed using descriptive statistics and ordinal logit analysis. The results show that a majority of participants affirmed that nutritional claim factors, purchasing behavior/food product factors, food safety factors, and healthy lifestyle factors are related to obesity. The results also show that age, race/ethnicity, "light" labeled food, nutritional label, low content carbohydrate food, and price are contributing factors to obesity. Furthermore, regular fitness activity and eating fruits and vegetables regularly had negative relationships with obesity, and therefore, can contribute to lowering the prevalence of obesity. Consequently, it was recommended that these eight factors should be considered in obesity education programs for residents in the study area.
\end{abstract}

Keywords: Obesity, Overweight, Factors, Alabama Black Belt

\title{
1. Introduction
}

According to the WHO (2014, p. 1), overweight and obesity are defined as "abnormal or excessive fat accumulation that may impair health." However, the Alabama Obesity Health Task Force (2005, p. 4) defined obesity as an "excessively high amount of body fat or adipose tissue in relation to lean body mass." WHO (2014) reported that obesity has almost doubled since 1980, and that in 2008, over 1.4 billion adults were overweight. Of this number, more than 200 million men and almost 300 million women were obese. On the whole, 35\% and $11 \%$ of the adult population were, respectively, overweight and obese in 2008 . WHO also reported that, in many countries, overweight and obesity kills more people than underweight does.

The Centers for Disease Control and Prevention [CDC] (2014a) stated that: (1) obesity is common, serious and costly, and (2) obesity affects some groups more than others. Regarding the former, the CDC intimated that over one-third of U.S. adults were obese; that obesity is related to several diseases, and the estimated annual medical cost linked to obesity in the U.S. was $\$ 147$ billion in 2008; adding that the costs for people who were obese was nearly $\$ 1,430$ higher compared to those who were of normal weight. Considering the latter, the CDC stated that Blacks have the highest rates of obesity, followed by Hispanics, Whites, and Asians; also that obesity is higher for middle-aged adults (40-59 years) than for younger (20-39 years) or older (60 years or older) adults. The CDC also mentioned that obesity prevalence appear linked to states and regions. For instance, in 2012, the top 13 states with most obesity prevalence were: Louisiana, Mississippi, Arkansas, West Virginia, Alabama, Oklahoma, South Carolina, Indiana, Kentucky, Michigan, Tennessee, Iowa, and Ohio, with prevalence of $30 \%$ or higher. In addition, prevalence of adult obesity was highest in the Midwest, 29.5\%; 
followed by the South, 29.4\%; Northeast, 25.3\%; and West 25.1\%.

The Alabama Obesity Task Force (2005) also observed that disparities in overweight and obesity prevalence exist among various groups in society based on race/ethnicity, gender, age, and socioeconomic status. Consequently, overweight and obesity are common in minority populations and those with lower household incomes. The Task Force emphasized that the likelihood of adult obesity increases as overweight children grow older. It stressed that $50 \%$ of children who are overweight at age of 6 years will become overweight as adults; what's more, by adolescence, this probability increases to $80 \%$.WHO $(2014$, p. 2) attributed the cause of overweight and obesity to an energy imbalance between caloric inflow and outflow. According to the WHO, globally, there has been: (1) an increase in the intake of energy-dense foods that are high in fat; and (2) a decrease in physical activity. It further stressed that overweight and obesity increase the risk for cardiovascular diseases (heart disease and stroke), diabetes, musculoskeletal disorders (especially osteoarthritis), and some cancers (endometrial, breast, and colon). It observed that overweight and obesity are preventable.

The CDC (2014a) reported that Alabama had a prevalence of obesity rate of 33\%, in 2012, ranking as the fifth most obese state in the nation; still, in 2011, its prevalence rate was over $30 \%$. Over time, most of the obesity prevalence is coming from the part of the State known as the Black Belt, representing mostly the South Central part of the State. The Center for Economics and Business Research (2014) identified these counties as: Barbour, Bullock, Butler, Choctaw, Crenshaw, Dallas, Greene, Hale, Lowndes, Macon, Marengo, Montgomery, Perry, Pike, Russell, Sumter, and Wilcox. The CDC (2014b) reported that these counties had aged adjusted obesity prevalence rates of $33.1 \%$; 33.9\%; 34.6\%; 35.8\%; 36.4\%; 38.3\%; $39.8 \%$, and $39.9 \%$ for $2004,2005,2006,2007,2008,2009,2010$, and 2011, respectively.

Furthermore, several factors are known to affect obesity. However, insofar as the authors are aware, there has not been any research, let alone empirical research, done on factors affecting obesity in the Alabama Black Belt. Therefore, a serious need exists to conduct such a study. Based on the preceding contention, the purpose of the study was to analyze factors affecting obesity in the Alabama Black Belt and surrounding counties. Specific objectives were to (1) identify and describe socioeconomic factors, (2) describe and assess other factors associated with obesity, (3) develop a model for obesity, and (4) estimate the extent to which the factors influence obesity.

\section{Literature Review}

Previous studies have shown that several factors affect obesity. These factors include gender, race, age, education, income, nutrition, and physical activity, among others. For instance, Miljkovic, Nganje, \& de Chastenet (2008) examined factors affecting the increase in obesity in the U.S. based on differential response to price, using multinomial logit analysis and data from the behavioral risk factor surveillance system (BRFSS), CDC, and USDA National Agricultural Statistics Service. The variables consisted of prices and other continuous, dummy, and count variables. Prices of sugar, potatoes, and whole milk were used as a proxy to reflect the consumption behavior of the respondents and their BMI categories: sugar represented the sweetner category; potatoes represented carbohydrate category; and whole milk represented the fat category. The continuous variables were: age, income, and education; 
dummy variables were: gender, trend (time), regions, and races; and count variables were: fruit and vegetable consumption. Of their sample, $43 \%$ were of normal weight; $40 \%$ were overweight; and 17\% were obese. Regarding prices, they reported that: (1) higher current prices of sugar significantly decreased the probability of being overweight and obese; however, the probability of being overweight and obese significantly increased with higher future prices of sugar; (2) current price of potatoes was significant and positive with being overweight and obese; the impact of historical and future prices for potatoes was negative and significant. That is, higher future potato prices will decrease probability of being overweight and obese through less consumption; and (3) higher current and future prices of milk will decrease prevalence of overweight and obesity.

Regarding consumption of fruits and vegetables, Miljkovic et al. (2008) also reported that as individuals consume less fruits and vegetables, the prevalence of overweight and obesity increase. Considering demographic continuous variables, they found that: (1) the prevalence of overweight and obesity increased with age, irrespective of gender; (2) as household income increased, consumers were less prone to be overweight and obese; also, (3) as education increased, consumers were less prone to be overweight and obese. Finally, considering demographic dummy variables, they found that: (1) the BMI trend was significant and positive for overweight and obese groups; (2) men were less likely to be obese than women; (3) generally, minorities were more prone to be overweight and obese compared to Whites, with the exception of Asians and Pacific Islanders; and (4) individuals from California (West) were less prone to be overweight and obese than those from Michigan (Midwest); too, individuals in Minnesota (Midwest) and Idaho (West) were less prone to be overweight and obese compared to those living in Michigan; on the contrary, individuals living in Texas (South), had the propensity to be overweight and obese compared to those living in Michigan.

Furthermore, Ogden, Lamb, Carroll, \& Flegal (2010) analyzed obesity and socioeconomic status in adults in the U.S., 2005-2008, based on data from the national health and nutrition examination survey by the CDC, and focusing mainly on income and education. They found that among men, the prevalence of obesity was generally identical at all levels of income, but among minority men, those with higher incomes were more likely to be obese than those with lower income. Women with higher incomes, on the contrary, showed a higher propensity to be obese than women with lower incomes. In addition, they found that there was no significant association between obesity and education for men. However, for women, those with college degrees had a lower propensity to be obese relative to those with lower levels of education. They also found that, the prevalence of obesity has risen in adults at all levels of income and education over the last decade in the U.S.

Relatedly, Akil \& Ahmad (2011) assessed the effects of socioeconomic factors on obesity rates in four southern states and Colorado, using BRFSS, Census Bureau, U.S. Department of Labor (DOL), and U.S. Department of Agriculture (USDA) data and regression analysis (PROC REG). They focused on gender, ethnicity, and geographic location (BRFSS); income level, percent below poverty level (Census Bureau); unemployment rates (DOL); and persons receiving food stamps (USDA). Like the previous authors, they also found that obesity rates had steeply increased in the U.S. over the last decade, $21.3 \%$ overall; Mississippi had the 
highest rate, 26.5\%; followed by Alabama (25.2\%); Louisiana (24.6\%); Tennessee (23.8\%); and Colorado (15.4\%). The four southern states were significantly different in terms of obesity prevalence from Colorado. Also, obesity rates were higher for African Americans compared to other groups in all states; Mississippi had the highest rate (35.5\%). The mean rate for males in the U.S. was $21.8 \%$, and that for females was $20.8 \%$. These rates were not significantly different from each other.

Additionally, Akil \& Ahmad reported that poverty rates, percent of people receiving food stamps, and unemployment rates reflected significant differences over time. Colorado had the highest income level with a mean of $\$ 48,158$; the lowest percent of people below poverty, $10.1 \%$; lowest unemployment rate, $4.7 \%$; and lowest proportion of people receiving food stamps, $4.8 \%$. These values were significant relative to those for the other four states. Mississippi reflected the lowest income level with a mean value of $\$ 32,165$; the highest proportion of people below poverty, $19.2 \%$, and the highest rate of unemployment, $6.5 \%$; whereas, Louisiana reflected the highest proportion of people receiving food stamps, $14.4 \%$. In addition, the authors regressed percent of people receiving food stamps, unemployment rate, income level, and percent of people living below the poverty level on obesity, measured as BMI. The $\mathrm{R}^{2}$ was 0.77 or $77 \%$, a very high variation in obesity due to the explanatory variables. When the explanatory variables were regressed singly (simple regressions), the $\mathrm{R}^{2}$ was 0.44 for percent of people living below the poverty level; 0.43 for percent of people receiving food stamps; 0.10 for unemployment rate; and 0.02 for income level, a very low correlation or variation for the latter; thus, income contributed little to the obesity rate.

Moreover, Noppa \& Bengtsson (1980) assessed obesity in relation to socioeconomic status of women in Sweden, using a survey and multiple regression analysis. There were two clusters of respondents, married and single, and the independent variables for married were age, husband's social class, husband's income, husband's age, education, and number of children. The independent variables for singles were age, own social class, own income, education, and number of children. They reported that for married women, age, husband's social class, husband's income, education, and number of children were significant factors affecting obesity; however, for single women, age and own income were significant factors affecting obesity.

A study by Musaiger, Al-Mulla, \& Al-Mannai (2000) investigated social, lifestyle and health factors associated with obesity among out-patients in Qatar, using interview and logit analysis. They found that age, gender, marital status, education, smoking status, and physical activity had relations with obesity, though not significant. Specifically, they found that the risk for obesity was more pronounced: (1) for older patients than younger patients; (2) for females than males; (3) for married persons than singles; (4) for those with higher educational levels than otherwise; (5) for smokers than non-smokers; and (6) for those who watched over two hours of television per day.

Also, Cavaliere \& Banterle (2008) assessed economic factors affecting obesity in Italy, using logit regression analysis. They focused mainly on socio-demographic and individual attributes (age, gender, work, education, income, components of family, and food knowledge); nutritional claim attributes (contents of energy, fat, sugar, sodium, fiber-vitamin, light, presence of nutritional label, and use of nutritional labeled information); purchasing 
behavior/food product attributes (price, brand, flavor, nutritional properties, origin of products, traceability, and quality certification); food safety attributes (attention to food safety issues, expiry dates, and ingredients); and healthy lifestyle attributes (exercise, dietary habits, and smoking status). For socio-demographic variables, they found that obesity increased with age; was more likely to occur in men than women; had a negative relationship with education; and had no significant relationship with income. Also, regarding purchasing behavior variables, there was an inverse and significant effect for flavor and nutritional properties. There were no significant effects regarding nutritional claim variables, food safety variables, and healthy lifestyle variables.

Similarly, Banterle \& Cavaliere (2009) assessed the social and economic determinants of obesity in Italy, using ordinal logit regression analysis. Again they focused on socio-demographic attributes (age, gender, work, education, income, components of family, and food knowledge); nutritional claims attributes (contents of energy, fat, sugar, sodium, fiber-vitamin, light, presence of nutritional label, and use of nutritional labeled information); purchasing behavior/food product attributes (price, brand, flavor, nutritional properties, origin of products, traceability, and quality certification); food safety attributes (attention to food safety issues, check expiry dates, and check ingredients); and healthy lifestyle attributes (exercise, dietary habits, and smoking status). The authors re-categorized some of the independent variables into three sub-categories, labeled as: factor $(F) 1$, nutritional label and claims attributes (low energy, low fat, low sugar, low sodium, high fiber-vitamin, light, and nutritional label); F2, product quality attributes (nutritional properties, origin of products, traceability, certification of quality, and food safety); and F3, product marketing attributes (price, brand, and flavor). The researchers reported that obesity was significantly and positively affected by age and number of family members; and significantly and negatively affected by gender and education. In addition, obesity was significantly and negatively related to fitness activity; that is, participating in fitness activity decreased obesity. Moreover, product quality variables and product marketing variables had a negative and significant effect on obesity, meaning that attributes such as nutritional properties, origin, traceability, certification, food safety, price, brand, and flavor are less likely to influence the decisions of overweight and obese consumers. Nutritional label and claims variables did not have a significant effect on obesity.

Also, the National Obesity Observatory (2012) evaluated adult obesity and socioeconomic status in England, using interview and descriptive statistics. It focused on income, occupation, education, and residency. It reported that: (1) obesity for women increased steadily with decreasing household income; the difference in the prevalence between the highest and lowest income groups was significant. For men, the variations were smaller and the trend was less clear; (2) there was a strong association between obesity prevalence and occupation-based social class for both men and women. Those with professional occupations had a lower obesity prevalence than those in unskilled or lower occupations; (3) obesity prevalence was higher among men and women with lower educational levels; and (4) women living in more deprived areas had higher levels of obesity than those in less deprived areas; the pattern for men was not clear. 


\section{Methodology}

\subsection{Data Collection}

A questionnaire was developed, using a format adapted from Banterle and Cavaliere (2009) with permission, and with some modifications. It was then used to collect the data for the study. It had five sections: nutritional claim attributes, purchasing behavior/food product attributes, food safety attributes, healthy lifestyle attributes, and demographic attributes. The questionnaire was submitted to the Human Subjects Committee of the Institution for approval before being administered. The questionnaire was administered to a convenience sample of residents from several Alabama Black Belt and surrounding counties, namely, from: Barbour, Bullock, Butler, Choctaw, Dallas, Greene, Hale, Lowndes, Macon, Marengo, Montgomery, Perry, Sumter, Wilcox (Black Belt Counties), Lee, Elmore, Chambers, Tallapoosa, and Autauga (surrounding counties).

The Black Belt and surrounding counties were chosen, because as indicated earlier, the CDC (2014a) stated that Alabama had obesity prevalence rate of 33\% in 2012, ranking fifth in the nation; in 2011, its prevalence rate was over 30\%. Also, CDC (2014b) attributed the high obesity prevalence rate to the Black Belt Counties, mainly in the South Central part of the state. Convenience sampling was adopted in this study, because of the lack of a known sampling frame from which subjects could be selected. The data were collected through interviews at various sites in the afore-mentioned counties, from summer 2012 to summer 2013. The total sample was 273 ; this was considered adequate for the study.

\subsection{Data Analysis}

The data were analyzed by using descriptive statistics and ordinal logit regression analysis. The regression model used a modified version of the one used by Banterle \& Cavaliere (2009), and is stated as follows:

$$
\mathrm{C}_{\mathrm{j}}\left(\mathrm{X}_{\mathrm{i}}\right)=\ln \left[P\left(\mathrm{Y}>\mathrm{j} \mid \mathrm{X}_{\mathrm{i}}\right) / P\left(\mathrm{Y} \leq \mathrm{j} \mid \mathrm{X}_{\mathrm{i}}\right)\right]=\beta_{1} \mathrm{X}_{\mathrm{i} 1}+\ldots+\beta_{\mathrm{n}} \mathrm{X}_{\mathrm{in}}-\tau_{\mathrm{j}}+1
$$

Where:

$\mathrm{C}_{\mathrm{j}}\left(\mathrm{X}_{\mathrm{i}}\right)=$ cumulative odds of being at or below category $\mathrm{j}$ of an ordinal variable with $\mathrm{k}$ categories, $1 \leq \mathrm{j} \leq \mathrm{k}-1$

$\mathrm{i}=$ number of participants considered

$\mathrm{j}=$ score for a category

$\mathrm{Y}=$ dependent variable

$\mathrm{n}=$ number of independent variables

$\mathrm{X}_{\mathrm{i}}=$ independent variables

$\beta_{\mathrm{i}}=$ coefficients

$\tau=$ cut points between categories

The empirical model is stated as:

$$
\ln (P \mathrm{BMI}>\mathrm{j} / \mathrm{PBMI} \leq \mathrm{j})=\beta_{1} \mathrm{SEF}+\beta_{2} \mathrm{NCF}+\beta_{3} \mathrm{PBF}+\beta_{4} \mathrm{FSF}+\beta_{5} \mathrm{HLF}-\tau+1
$$

Where:

$\ln (P \mathrm{BMI}>\mathrm{j} / P \mathrm{BMI} \leq \mathrm{j})=$ cumulative odds of being at or below a body mass index (BMI) 
category.

$\mathrm{SEF}=$ Socioeconomic factors

$\mathrm{NCF}=$ Nutritional claim factors

$\mathrm{PBF}=$ Purchasing behavior/food product factors

$\mathrm{FSF}=$ Food safety factors

HLF $=$ Healthy lifestyles factors

In brief, the estimated model hypothesizes that obesity is influenced by socioeconomic factors; nutritional claim factors; purchasing behavior/food product factors; food safety factors; and healthy lifestyle factors. It was assumed that the expected signs of the independent variables were not known a priori. The details of the variable names and descriptions used for the model are shown in Tables 1 and 2.

In the study, obesity was measured as BMI (and it is the dependent variable). According to the CDC (2011), the BMI is generally a reliable measure of body fatness. It emphasized that although the BMI does not directly determine body fat, it associates closely with measures of body fat. BMI can be calculated in two ways, either metric (kilograms and meters squared) or English (pounds and inches squared). The two formulas are as follows:

Metric:

$$
\mathrm{BMI}=\mathrm{wt}(\mathrm{kg}) /[\mathrm{ht}(\mathrm{m})]^{2}
$$

English:

$$
\mathrm{BMI}=\mathrm{wt}(\mathrm{lb}) /[\mathrm{ht}(\mathrm{in})]^{2} \times 703
$$

The CDC explained that BMI is interpreted using weight categories that are identical for adults, ages 20 years or older. Subjects were allowed to self-report their heights (in inches) and weights (in pounds) and these were used to calculate the BMIs. Table 2 provides a summary of the weight categories, indices, and various descriptions. The ordinal logistic regression analysis was run for the model, using SPSS12.0 ${ }^{\odot}$ (MapInfo Corporation, Troy, NY). The criteria used to assess the model were the model chi-square, beta coefficients, and $p$ values.

\section{Results and Discussion}

\subsection{Descriptive Results}

Table 3 shows the socioeconomic attributes of the respondents. About $69 \%$ were females and $31 \%$ were males; $79 \%$ were Blacks; $58 \%$ were 44 years or younger, whereas $42 \%$ were over 44 years. Considering education and income, $61 \%$ had, at least a two-year college education, while $39 \%$ had high school education or less; $64 \%$ earned $\$ 30,000$ or less and $36 \%$ earned over $\$ 30,000$. Also, $57 \%$ were single or married/cohabiting without children in the household, and $43 \%$ were single parents or married/cohabiting with at least one child. The socioeconomic attributes reflected a higher proportion of females than males; a higher proportion of Blacks than Whites; a higher proportion with at least some college education or two-year degree than otherwise; a higher proportion earning less than $\$ 30,000$ than otherwise; and a higher proportion living with no child at home than otherwise. Moreover, the BMI 
proportions showed that $27 \%$ were of normal weight, $31 \%$ were overweight, and $39 \%$ were obese.

Table 1. Variable Definitions and Description of Data

Variable Description Mean Standard Deviation

\section{Socioeconomic Factors}

$\begin{array}{ll}0 & =\text { male } \\ 1 & =\text { female } \\ 1 & =\text { other } \\ 2 & =\text { White } \\ 3 & =\text { Black } \\ 1 & =20-24 \\ 2 & =25-34 \\ 3 & =35-44 \\ 4 & =45-54 \\ 5 & =55-64 \\ 6 & =65 \text { and above } \\ 1 & =\text { elementary/middle } \\ 2 & =\text { high school/GED } \\ 3 & =\text { two-year/technical } \\ 4 & =\text { some college } \\ 5 & =\text { college degree } \\ 1 & =\$ 10,000 \text { or less } \\ 2 & =\$ 10,001-20,000 \\ 3 & =\$ 20,001-30,000 \\ 4 & =\$ 30,001-40,000 \\ 5 & =\$ 40,001-50,000 \\ 6 & =\$ 50,001-60,000 \\ 7 & =\text { more than } \$ 60,000 \\ 1 & =\text { single, living alone } \\ 2 & =\text { married/cohabiting, no child } \\ 3 & =\text { single parent, a child } \\ 4 & =\text { married/cohabiting, a child } \\ \text { Household income } & 3.18 \\ \text { Marital status } & \end{array}$

Nutritional Claim Factors

Carbohydrate

$$
\begin{aligned}
& 0=\text { strongly disagree } \\
& 1=\text { disagree }
\end{aligned}
$$


Fat

$2=$ neutral

3 = agree

$4=$ strongly agree

Fat

$0=$ strongly disagree

2.76

1.06

$1=$ disagree

$2=$ neutral

$3=$ agree

$4=$ strongly agree

Sugar

$0=$ strongly disagree

2.68

1.15

$1=$ disagree

$2=$ neutral

$3=$ agree

$4=$ strongly agree

Sodium

$0=$ strongly disagree

$1=$ disagree

$2=$ neutral

$3=$ agree

$4=$ strongly agree

Fiber/vitamin

$0=$ strongly disagree

$1=$ disagree

$2=$ neutral

$3=$ agree

$4=$ strongly agree

Light

$0=$ strongly disagree

$1=$ disagree

$2=$ neutral

$3=$ agree

$4=$ strongly agree

Label presence

$0=$ strongly disagree

$1=$ disagree

$2=$ neutral

$3=$ agree

$4=$ strongly agree

Label information

$0=$ no

$1=$ yes

Purchasing Behavior/Food Product Factors

Price

$0=$ strongly disagree

0.94 
Brand

$1=$ disagree

$2=$ neutral

3 = agree

$4=$ strongly agree

$0=$ strongly disagree

$1=$ disagree

$2=$ neutral

$3=$ agree

$4=$ strongly agree

Flavor

$0=$ strongly disagree

$1=$ disagree

$2=$ neutral

$3=$ agree

$4=$ strongly agree

Properties

$0=$ strongly disagree

$1=$ disagree

$2=$ neutral

$3=$ agree

$4=$ strongly agree

Origin

$0=$ strongly disagree

$1=$ disagree

$2=$ neutral

$3=$ agree

$4=$ strongly agree

Traceability

$0=$ strongly disagree

$1=$ disagree

$2=$ neutral

$3=$ agree

$4=$ strongly agree

Certification

$0=$ strongly disagree

$1=$ disagree

$2=$ neutral

$3=$ agree

$4=$ strongly agree

Food Safety Factors

Food Safety

$0=$ strongly disagree

$1=$ disagree 


$$
\begin{aligned}
& 2=\text { neutral } \\
& 3=\text { agree } \\
& 4=\text { strongly agree }
\end{aligned}
$$

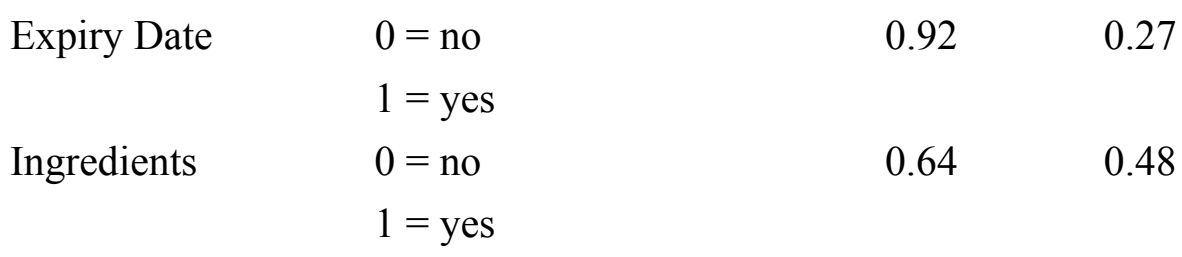

Healthy Lifestyle Factors

$\begin{array}{rlrr}\text { Fitness Activity } & =\text { no } & 0.54 & 0.50 \\ \text { Smoke } & =\text { yes } & & \\ 0 & =\text { no } & & \\ 1 & =\text { yes } & & \\ \text { Fruits and Vegetables } 0 & =\text { no } & & \\ 1 & =\text { yes } & & \\ & & & \end{array}$

Table 2. Description of BMI Categories and Variable Definitions

\begin{tabular}{lllll}
\hline Category & BMI & Description & Mean & Standard Deviation \\
\hline Underweight & Below 18.5 & 1 & 3.05 & 0.89 \\
Normal & $18.5-24.9$ & 2 & & \\
Overweight & $25.0-29.9$ & 3 & & \\
Obese & 30 and above & 4 & & \\
& & & & \\
\hline
\end{tabular}

Table 4 presents the responses regarding nutritional claim attributes. About $58 \%$ of respondents agreed or strongly agreed that choosing a food that has low carbohydrate content was important to them. Also, $66 \%$ agreed or strongly agreed that choosing a food that has low fat content/fat free was important to them. Exactly $63 \%$ agreed or strongly agreed that choosing a food that has low sugar content/sugar free was important to them. Approximately $67 \%$ agreed or strongly agreed that choosing a food that has low sodium content/sodium free was important to them. Furthermore, another $67 \%$ agreed or strongly agreed that choosing a food that has high fiber/vitamin content was important to them. Almost $49 \%$ agreed or strongly agreed that choosing a food that is labeled "light" was important to them. Nearly $76 \%$ agreed or strongly agreed that choosing a food that has its nutritional label was important to them. Not surprisingly, therefore, almost $62 \%$ affirmed that before purchasing a food item they checked its nutritional label information. 
Table 3. Responses Regarding Selected Socioeconomic Factors

Variable

Frequency

Percent

\section{Gender}

Male

Female

\section{Race/Ethnicity}

Black

White

Other

Age

18-24 years

25-34 years

35-44 years

45-54 years

65 years or older

\section{Education}

Middle School or Below 7

2.6

High School Graduate/GED

Two-Year/Technical College Degree

Some College

College Degree

\section{Annual Household Income}

$\$ 10,000$ or less

$\$ 10,001-20,000$

$\$ 20,001-30,000$

$\$ 30,001-40,000$

$\$ 40,001-50,000$

$\$ 50,001-60,000$

Over 60,000

\section{Marital Status}

Single, living alone

Married/Cohabiting without children

Single with at least one child

Married/Cohabiting with at least 
one child

BMI

Underweight

Normal

Overweight

Obese
9

At least, 58\% agreed or strongly agreed that choosing a food that has low carbohydrate content; low fat content/fat free; low sugar content/sugar free; low sodium content/sodium free; high fiber/vitamin content; and presence of its nutritional label was important to them.

Also, a majority checked a food's nutritional label information before purchasing the food. It appears that generally the content of food was a key factor in choosing food. This is not surprising as consumers may be becoming health conscious or aware. The question is: does this translate to "actionable behavior?" That is, do consumers behave positively with the information they have? For example, if the consumer says that choosing a low sodium food is important, does he actually consume foods with lower sodium? In addition, "light" labeled food did not appear to have relative importance to the consumer as the other attributes.

Table 4. Responses Regarding Nutritional Claim Factors

Variable

Frequency
Percent

Agree

78

Strongly Agree

Low Fat/Fat Free

Strongly Disagree

Disagree

Neutral

Agree

Strongly Agree

Low Sugar/Sugar Free

Strongly Disagree

Disagree

Neutral
27.1

38.5 
Agree

Strongly Agree

\section{Low Sodium/Sodium Free}

Strongly Disagree

Disagree

Neutral

Agree

Strongly Agree

Light

Strongly Disagree

Disagree

Strongly Agree

Label

Strongly Disagree

\section{5}

14

47

101

106

169

104

Strongly Agree

\section{Information}

3.3

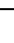

Table 5 reflects the responses regarding purchasing behavior/food product attributes. About $81 \%$ agreed or strongly agreed that when purchasing a food item, its price was important to them. Nearly $48 \%$ agreed or strongly agreed that when purchasing a food item, its brand was important to them. Exactly $85 \%$ agreed or strongly agreed that when purchasing a food item, its flavor was important to them. Nearly $74 \%$ agreed or strongly agreed that when purchasing a food item, its nutritional properties was important to them. Almost 54\% agreed or strongly agreed that when purchasing a food item, its origin was important to them. Exactly $56 \%$ agreed or strongly agreed that when purchasing a food item, its traceability was important to them. Approximately $77 \%$ agreed or strongly agreed that when purchasing a food item, its certification of quality was important to them. 
Table 5. Responses Regarding Purchasing Behavior/Food Product Factors

Variable $\quad$ Frequency $\quad$ Percent

\section{Price}

Strongly Disagree

Disagree

Neutral

Agree

Strongly Agree

\section{Brand}

Strongly Disagree

Disagree

Neutral

Agree

Strongly Agree

\section{Flavor}

Strongly Disagree

Disagree

Neutral

Agree

Strongly Agree

Nutritional Properties

Strongly Disagree

Disagree

Neutral

Agree

Strongly Agree

$$
78
$$

\section{Origin}

Strongly Disagree

Disagree

Neutral

Agree

Strongly Agree

46

16.8

\section{Traceability}

Strongly Disagree

Disagree

\section{2}


Neutral

72

95

58

Strongly Agree

Certification

Strongly Disagree

Disagree

Neutral

Agree

Strongly Agree
8

15

57

116

77
26.4

34.8

21.2

20.9

42.5

28.2

In this case, at least, 54\% agreed or strongly agreed that when purchasing a food item, its price; flavor; nutritional properties; origin; traceability; and certification of quality was important to them. Overall, it appears respondents were more concerned with flavor, price, nutritional properties, and certification, with at least $74 \%$ agreeing or strongly agreeing. What's more, the brand of the food item did not appear to have a high degree of importance to the consumer. In addition, the finding on nutritional properties in this case (majority, 74\% agreed or strongly agreed) is in sync with the "nutritional claim attribute" finding on nutritional label information of a majority (62\%) of respondents affirming that before purchasing a food item, they check its nutritional label information.

Table 6 presents responses regarding food safety attributes. Nearly $82 \%$ agreed or strongly agreed that they were concerned with food safety aspects of a food item. Almost $92 \%$ checked the expiry date of a food item; and 64\% read the list of ingredients of a food item. Since $82 \%$ agreed or strongly agreed that they were concerned with food safety aspects of a food item, a majority checked the expiry date, and read the list of ingredients of a food item. A tenable reason may be that they wanted to be certain of the status of the food item.

Table 7 depicts responses regarding healthy lifestyle attributes. About $54 \%$ of respondents participated in a fitness activity or exercised regularly; whereas $46 \%$ did not. Nearly $18 \%$ stated that they smoked regularly and $82 \%$ did not. Also, nearly $86 \%$ stated that they ate fruits and vegetables regularly and $14 \%$ did not. Although the majority of respondents did not smoke or eat fruits and vegetables regularly, many of them were overweight and obese (Table $3)$. This may be a confirmation of a higher proportion of them not exercising regularly versus eating fruits and vegetables regularly ( $54 \%$ versus $86 \%$ ). It may be a testament that eating fruits and vegetables alone may not be enough to reduce overweight and obesity.

\subsection{Regression Results}

Table 8 shows the estimates for the model. Overall, the model was highly significant ( $p=$ 0.006), with a chi-square value of 48.851 . This implies that, at least one or all of the factors jointly explain variation in obesity. For the socioeconomic factors, age and race/ethnicity 
Table 6. Responses Regarding Food Safety Factors

Variable

Frequency

Percent

Safety

Strongly Disagree

7

2.6

Disagree

12

4.4

Neutral

31

11.4

Agree

104

38.1

Strongly Agree

119

43.6

Expiry Date

Yes

252

92.3

No

21

7.7

Ingredients

Yes

175

64.1

No

98

35.9

Table 7. Responses Regarding Healthy Lifestyle Factors

Variable $\quad$ Frequency Percent

\section{Fitness Activity (Exercise)}

Yes

148

54.2

No

125

45.8

Smoke

Yes

49

17.9

No

224

82.1

Fruits and Vegetables

Yes

No

were highly significant and positive with obesity, respectively, as $p=0.001$ and $p=0.016$. For the former, it means that overweight and obesity increase with age. For the latter, it implies that overweight and obesity are far more likely for Blacks than Whites or other races. The results for age are consistent with those by Noppa \& Bengtsson (1980), Miljkovic et al. (2008), Cavaliere \& Banterle (2008), and Banterle \& Cavaliere (2009) who all found that age has a pronounced effect on overweight and obesity. Also, as people age, they tend to put on 
weight more if they do not watch what they eat and how they eat, all things equal. This could be a reason for the finding. The findings for race/ethnicity are also consistent with those found by Miljkovic et al. (2008) and Akil \& Ahmad (2011) who reported similar findings of

Table 8. Estimates of the Parameters for the Model

Variable

$\beta$

$P$

\section{Socioeconomic Factors}

Gender

0.214

0.454

Race/Ethnicity

$0.616^{* *}$

0.016

Age

$0.310 * * *$

0.001

Education

$-0.030$

0.790

Income

$-0.020$

0.810

Marital Status

0.009

0.930

\section{Nutritional Claim Factors}

Carbohydrate

$\begin{array}{ll}0.325 * * & 0.054 \\ 0.043 & 0.835\end{array}$

Fat

$-0.001$

0.997

Sugar

0.310

0.121

Fiber/vitamin

$-0.212$

0.233

Light

$-0.399 * * *$

0.018

Label

$-0.433 * * *$

0.017

Information

0.309

0.217

\section{Purchasing Behavior/Food Product Factors}

Price

$0.267^{*}$

0.061

Brand

$-0.060$

0.644

Flavor

0.218

0.218

Properties

0.000

1.000

Origin

0.140

0.395

Traceability

$-0.096$

0.576

Certification

0.190

0.290

Food Safety Factors

Safety

$-0.048$

0.336

Date

$-0.287$

0.577

Ingredients

$-0.226$

0.460

Healthy Lifestyle Factors

Activity 
Smoke

Chi-square

Nagelkerke
$48.851 * * *(p=0.006)$

0.180

*** Significant at $1 \% ; * *$ Significant at $5 \% ; *$ Significant at $10 \%$

Blacks being more likely overweight and obese than other races. Moreover, it is plausible that Blacks may be purchasing the wrong types of food or consuming obesity-prone foods; hence, the significant finding. Although gender, education, annual household income, and marital status were not significant, they seem to follow the pattern in the literature. That is, overweight and obesity are more likely for women than men, positive relationship; less likely for those with higher education, negative relationship; less likely for those with higher incomes, negative relationship; and more likely for those living with children in their households or in larger households, positive relationship.

For the nutritional claim factors, choosing a food that is labeled "light" or has its nutritional label was highly significant and negative, respectively, $p=0.018$ and $p=0.017$. This implies that overweight and obesity decrease by selecting "light" labeled food or food that has its nutritional label. Both of these factors were not significant for Cavaliere \& Banterle (2008) and Banterele \& Cavaliere (2009). However, it is not surprising that food that is labeled "light" is significantly and negatively related to obesity as food with decreased fats are supposed to reduce obesity. In the same vein, a food item that has its nutrition label most likely will attract consumers to read it, causing them to stay away from any items associated with obesity; hence, the negative relationship. In addition, choosing a food that has low carbohydrate content was highly significant and positive, $p=0.054$. This means that overweight and obesity increase by choosing a food that has low carbohydrate content. Again, this result is contrary to the results of Cavaliere \& Banterle (2008) and Banterele \& Cavaliere (2009) who found no significant relationship between nutritional claim factors and overweight and obesity. A plausible explanation for this result may be that the food that the respondents were choosing may not necessarily have low carbohydrate content or may be obesity-prone; consequently, increasing overweight and obesity. Fat, sugar, sodium, fiber/vitamin, and nutritional label information were not statistically significant. Two factors, fat and fiber/vitamin, draw attention; although not significant, fat increases overweight and obesity, positive relationship, and consuming fiber/vitamin decrease overweight and obesity, negative relationship.

For the purchasing behavior/food product factors, only price was significant and positive at $p$ $=0.061$. This means that overweight and obesity increased regardless of increases in the price of a food item. An explanation is that, although the price of the food item was important, respondents were attached or addicted to that food, which may be obesity-prone, regardless of price increases and they just stuck with that food item. Another plausible reason may be the non-availability of food which may be healthy and less obesity-prone with reasonable 
prices.

None of the food safety factors or the healthy lifestyle factors was significant. Considering the food safety factors, for example, although none was significant, they all seem to follow the literature and theory (negative relationships), implying that overweight and obesity decreased as respondents paid attention to food safety aspects of a food item; checked the expiry date of a food item; or read the list of ingredients of a food item. The results are in agreement with those of Banterle \& Cavaliere (2009). Similarly, focusing on the healthy lifestyle factors, they all also seem to follow the literature and theory (negative relationships). Here again, overweight and obesity decreased as respondents participated in a fitness activity or exercised, not smoking, or ate fruits and vegetables regularly. The implication is that exercising, not smoking, and eating fruits and vegetables regularly are a good thing. The results are quite in sync with those of Banterle \& Cavaliere (2009) and Musaiger, Al-Mulla, \& Al-Mannai (2000); although in the case of the former authors, fitness activity had a significant relationship with obesity.

\section{Conclusion}

The study analyzed factors affecting obesity in the Alabama Black Belt and surrounding counties. Specifically, it identified and described socioeconomic factors, described and assessed other factors associated with obesity, developed a model for obesity, and estimated the extent to which the factors influenced obesity. The results regarding socioeconomic attributes show, for example, a fairly highly educated group, with a relatively modest annual household income, and many with no children at home. There were also a high proportion of overweight and obese respondents. In addition, most (at least 58\%) agreed or strongly agreed with all (but one) statements regarding nutritional claim attributes. Similarly, most (at least $54 \%$ ) agreed or strongly agreed with all (but one) statements regarding purchasing behavior/food product attributes.

Moreover, a majority (at least 64\%) agreed or strongly agreed that they were concerned with food safety issues, or affirmed they checked the expiry date or read the list of ingredients on a food item; and a sizeable majority affirmed that they participated in fitness activity (54\%) or eat fruits and vegetables (86\%) regularly; however, an overwhelming majority (82\%) did not smoke. The ordinal logit analysis revealed that selected factors had significant effects on overweight and obesity: specifically, age and race/ethnicity among the socioeconomic factors; light, nutrition label, and low carbohydrate, among the nutritional claim factors; and price among the purchasing behavior/food product factors. Although other factors (gender, education, household income, marital status, concerns with food safety, checking expiry date, reading ingredients, regular fitness activity, not smoking, and eating fruits and vegetables regularly) were not significant, they followed the literature in terms of direction.

Based on the above, overweight and obesity can affect the lives of many individuals in the society, especially the Alabama Black Belt and surrounding counties. These findings show that there is a high prevalence of overweight and obesity in these counties, which may be associated with socioeconomic, nutritional claim, purchasing behavior/food product, food safety, and healthy lifestyle factors. Furthermore, based on the factors addressed, there is a need for obesity assistance and education providers to consider age; race/ethnicity; "light" 
labeled food; nutrition label; low carbohydrate content food; and price, as well as regular fitness activity or exercise, and eating fruits and vegetables regularly in obesity education in an effort to reduce obesity in the targeted area. The latter two factors, although not significant, displayed a negative relationship with obesity, and hence, their needed consideration in obesity education.

This study has contributed to further insights into how selected factors affect obesity, especially the Alabama Black Belt and surrounding counties, a mainly rural and relatively poor region. The results of the study also show that age; race/ethnicity; labeled "light"; nutrition label; low carbohydrate content food; and price are contributing factors to obesity. Additionally, regular fitness activity and eating more fruits and vegetables on a regular basis can contribute to lowering the prevalence of obesity because of their negative relationships with obesity. One limitation of the study is the use of convenience sampling; that is, it does not guarantee a fair representation of particular groups. Nonetheless, it is still used in research because of its ability to generate quick, important, and useful information that would not be possible using other means. It is recommended that similar studies be conducted in the Black Belt, using a larger sample size, covering a wider geographical area, and/or using different methodologies to see if these findings would replicate.

\section{References}

Alabama Obesity Task Force. (2005). Strategic plan for the prevention and control of overweight and obesity in Alabama, Alabama Department of Public Health, Montgomery, AL.

Akil, L, \& Ahmad, H. A. (2011). Effects of socioeconomic factors on obesity rates in four southern states and Colorado. Ethnicity and Disease, 21(1), 58-62.

Banterle, A., \& Cavaliere, A. (2009). The social and economic determinants of obesity: An empirical study in Italy. Presented at the $113^{\text {th }}$ EAAE Seminar, Chania, Greece, September 3-6. Retrieved August 15, 2013, from http://www.ageconsearch.umn.edu/bitstream/90889/2/Cavaliere.pdf

Cavaliere, A., \& Banterle, A. (2008). Economic factors affecting obesity: An application in Italy. Presented at the $12^{\text {th }}$ Congress of the European Association of Agricultural Economists, Ghent, Belgium. Retrieved July 28, 2013, from http://ideas.repec.org/p/ags/eaae08/44324.html

CDC. (2014a). Adult obesity facts. Retrieved July 25, 2014, from http://www.cdc.gov/obesity/data/adult.html

CDC. (2014b). Adult obesity prevalence data. Retrieved July 25, 2014, from http://www.cdc.gov/diabetes/atlas/countydata/OBPREV/data_Alabama.pdf

CDC. (2011). About BMI for adults. Retrieved July 25, 2014, from http://www.cdc.gov/healthweight/assessing/bmi/adult_bmi/index.html

Center for Economics and Business Research, The University of Alabama. (2014). Traditional Counties of the Alabama Black Belt. Retrieved March 17, 2014, from http://www.cber.cba.ua.edu/edata/maps/images/PDFs/blackbelt.pdf

Miljkovic, D., Nganje, W, \& de HChastenet, H. (2008). Economic factors affecting the 
increase in obesity in the United States: differential response to price. Food policy, 33, 48-60. htpp://dx.doi.10.1016/j.foodpol.2007.05.003.

Musaiger, A., Al-Mulla, A. A., \& Al-Mannai, M. A. (2000). Social lifestyle and health factors associated with obesity among out-patients in Qatar. Retrieved August 10, 2013, from http://www.bahrainmedicalbulletin.com/September_2000/Obesity_qatar.pdf

National Obesity Observatory. (2012). Adult obesity and socioeconomic status. NOO Fact Sheet. Retrieved July 10, 2014, from http://www.noo.org.uk

Noppa, H., \& Bengtsson, C. (1980). Obesity in relation to socioeconomic status: A population study of women in Goteborg, Sweden. Journal of Epidemiology and Community Health, 34, 139-142. http://dx.doi.org/10.1136/jech.34.2.139

Ogden, C. L., Lamb, M. M., Carroll, M. D., \& Flegal, K. M. (2010). Obesity and socioeconomic status in adults: United States, 2005-2008. National Data Briefs, 50, 1-10.

WHO. (2014). Obesity and overweight. Retrieved July 25, 2014, from http://www.who.int/mediacenter/factsheets/fs311/en/\#

\section{Copyright Disclaimer}

Copyright reserved by the author(s).

This article is an open-access article distributed under the terms and conditions of the Creative Commons Attribution license (http://creativecommons.org/licenses/by/3.0/). 